\title{
Revista \\ HISTÓRIA DA ENFERMAGEM Brasileira de Enfermagem REBEn \\ Ensino de Graduação em Enfermagem: a contribuição da Associação Brasileira de Enfermagem
}

\author{
Teaching in Undergraduate Nursing: the contribution of Brazilian Nursing Association \\ Enseñanza de Graduación en Enfermería: la contribuición \\ de la Asociación Brasilera de Enfermería
}

\section{Eucléa Gomes Vale}

Mestre em Educação. Coordenadora do Curso de Graduação em Enfermagem da Faculdade Católica Rainha do Sertão, Quixadá,CE. Doutoranda em Enfermagem pela Universidade Federal do Ceará. euclea@terra.com.br

Josicelia Dumêt Fernandes

Doutora em Enfermagem. Professora Titular da Escola de Enfermagem da Universidade Federal da Bahia, Salvador, BA. Membro da Comissão Assessora de Avaliação da área de Enfermagem do INEP/MEC. Membro do Grupo de Estudos e Pesquisas em Educação, Ética e Exercício de Enfermagem. Pesquisadora do CNPq. dumet@ufba.br

Submissão: 30/05/2005

Aprovação: 30/08/2006

\section{RESUMO}

O presente estudo apresenta algumas das ações mais relevantes da Associação Brasileira de Enfermagem para com o processo de formação da(0) enfermeira(0), no país, contextualizando essas ações com o momento histórico em que elas aconteceram. Nesse sentido, o estudo se constitui, não só, numa produção de conhecimento na área, mas também num elemento de registro da história do ensino de graduação em enfermagem no Brasil, oferecendo instrumentos de análise para a situação atual desse ensino. O texto destaca as contribuições da ABEn no processo de formação da enfermeira, na construção e sustentabilidade das Diretrizes Curriculares Nacionais do Curso de Graduação em Enfermagem.

Descritores: Sociedades de enfermagem; Educação em enfermagem; História da enfermagem

\section{ABSTRACT}

The present study shows some of the most relevant actions of the Brazilian Association of Nursing in favor of the education process of the nursing professionals in Brazil, contextualizing those actions in the historical moment in which they occurred. In this manner, the study represents not only production of knowledge in the field, but also an element of record of the history of undergraduate nursing teaching in Brazil, offering instruments of analysis of the current situation of this teaching. The text highlights the contributions of the Brazilian Association of Nursing (ABEn) in the education process of the nursing professionals, and in the elaboration and sustainability of the National Curricular Guidelines of the Undergraduate Nursing Course.

Descriptors: Societies, nursing; Education, nursing; History of nursing.

\section{RESUMEN}

El presente estudio presenta algunas de las acciones más relevantes de la Asociación Brasileña de Enfermería para con el proceso de formación del (de la) enfermero(a), en el país, contextualizando esas acciones con el momento historico en que ellas acontecieron. En ese sentido, el estudio se constituye, no sólo, en una producción de conocimiento en el área, pero también en un elemento de registro de la historia de la enseñanza de graduación en enfermería en el Brasil, ofreciendo instrumentos de análisis para la situación actual de esa enseñanza. El texto señala las contribuciones de la ABEn en el proceso de formación de la enfermería, en la construcción y sustentabilidad de las Directrices Curriculares Nacionales para la Graduación en Enfermería.

Descriptores: Sociedades de enfermería; Educación en enfermería; Historia de la enfermeria.

Vale EG, Fernandes JD. Ensino de Graduação em Enfermagem: a contribuição da Associação Brasileira de Enfermagem. Rev Bras Enferm 2006; 59(esp): 417-22.

\section{INTRODUÇÃO}

AAssociação Brasileira de Enfermagem (ABEn), em sua trajetória de lutas pela democracia, ética e compromisso com a enfermagem brasileira, tem alavancado ações em defesa da vida e da formação de profissionais comprometidos com a qualidade de vida da população, com a justiça social e com a garantia da cidadania.

Nesse caminhar, aABEn, desde a sua criação, vem dedicando uma grande parcela de seu trabalho, às questões da educação em enfermagem, em parceria com os órgãos formadores e com as instâncias do Ministério da Educação que se destinam a regulamentar e avaliar a formação de profissionais da área da saúde.

Essa entidade vem desenvolvendo um papel importante e decisivo nos avanços e conquistas do processo de formação das(os) profissionais de enfermagem. Vem promovendo discussões e reflexões, congregando e mobilizando enfermeiras(os) docentes e assistenciais, bem como estudantes de 
enfermagem, em busca da construção de estratégias e propostas pedagógicas que contribuam para a formação de profissionais que atendam à demanda social.

Neste ano de 2006, quando a ABEn comemora os seus 80 anos de existência, as autoras do presente texto consideram de grande importância apresentar algumas das ações mais relevantes dessa entidade para com o processo de formação da(0) enfermeira(0), no país. Nesse sentido, 0 presente texto pretende se constituir, não só, numa produção de conhecimento na área, mas também num elemento de registro da história do ensino de graduação em enfermagem no Brasil, oferecendo instrumentos de análise para a situação atual desse ensino.

Sob essa ótica, o presente texto tem como objetivo apresentar algumas das ações mais relevantes da contribuição da $A B E n$ com o ensino de graduação em enfermagem no Brasil, contextualizando essas ações com o momento histórico em que elas aconteceram.

\section{A ABEN E A FORMAÇÃO DA(0) ENFERMEIRA(0)}

\section{Um pouco da história}

A ABEn foi criada em 1926, com a denominação de Associação Nacional de Enfermeiras Diplomadas Brasileiras. Em 1944, com a reforma do seu estatuto, essa entidade passou a chamar-se Associação Brasileira de Enfermeiras Diplomadas (ABED) e, somente a partir de 1954, passou a ter a denominação de Associação Brasileira de Enfermagem (ABEn) ${ }^{(1)}$.

A preocupação dessa entidade com as questões da educação em enfermagem está confirmada no seu primeiro estatuto, datado de 1929, com o seguinte registro, ao se referir aos fins da Associação: "Trabalhar incessantemente pelo progresso da educação de enfermeiras e pelo estabelecimento de escolas de enfermagem que tenham os mesmos requisitos da Escola Oficial do Governo"(1).

Considerando que a maior demanda dessa entidade estava direcionada para as questões da educação em enfermagem, em 1939 foi organizada a Comissão de Educação que tinha como finalidade auxiliar a diretoria da entidade nas suas atividades de elaboração e acompanhamento dos projetos de criação de novas escolas ${ }^{(1)}$. Essa Comissão, em 1945, foi denominada Divisão de Ensino de Enfermagem e, logo em seguida, foi denominada Divisão de Educação, a qual foi integrada pelo corpo docente das escolas de Enfermagem e pelas superintendentes de serviços ${ }^{(1)}$.

Essa Divisão tinha como objetivos:

1)estudar todos os assuntos relacionados ao ensino de enfermagem;

2)procurar melhorar os padrões de Enfermagem a fim de prestar melhor assistência ao público;

3)cooperar com a Associação no sentido de desenvolver o senso de responsabilidade e interesse pelos assuntos referentes à Enfermagem entre os membros que se dedicavam a administração das escolas, ao ensino e à supervisão de estudantes ${ }^{(1)}$.

A Divisão de Educação teve um papel de destaque na organização do primeiro Congresso de Enfermagem, realizado em 1947, que teve como um dos temas de destaque, as questões ligadas ao ensino de graduação em enfermagem ${ }^{(1)}$.

Em parceria com a Divisão de Saúde Pública da ABED, a Divisão de Educação organizou cursos em administração e ensino para enfermeiras chefes, em todo o país. As reuniões realizadas entre estas duas Divisões culminaram com o reconhecimento da necessidade premente de criação de cursos para a formação de enfermeiras chefes e instrutoras de ensino ${ }^{(1)}$.

O relatório da Divisão de Educação, apresentado no primeiro Congresso Nacional de Enfermagem, em 1947, teve como objetivos para esta Divisão:

1) organizar o programa de um curso básico de enfermagem para todas as enfermeiras, de modo a torná-las aptas a prestarem melhores cuidados de enfermeiras diplomadas e o tipo de preparo necessário ao bom desempenho de suas funções, nos vários ramos de serviços;

2) preparar o currículo teórico mínimo para curso de enfermagem;

3) fixar a duração dos estágios práticos nas diversas clínicas;

4) estabelecer normas para o preparo das auxiliares de enfermagem ${ }^{(1)}$.

Em abril de 1949, a Divisão de Educação da ABED indicou uma Comissão Especial para elaboração de um projeto que subsidiou a elaboração da Lei $n^{0} 775 / 49$ que institucionalizou o ensino de enfermagem no país como matéria de Lei( ${ }^{(1,2)}$.

O reconhecimento do ensino de enfermagem como matéria de Lei, contudo, não foi dado gratuitamente para a enfermagem. Ele foi o resultado de pressões das profissionais de enfermagem que, através da $A B E n$, lutavam pela garantia e reconhecimento de sua profissão.

Em 1954, a ABED passou a denominar-se Associação Brasileira de Enfermagem (ABEn) e, em 1955, a Divisão de Educação passou a chamarse Comissão de Educação.

Em 1961, em decorrência da Lei de Diretrizes e Bases da Educação Nacional (Lei no 4024 de 20 de dezembro de 1961), a ABEn apresentou sugestões ao Conselho Federal de Educação para a construção de novo currículo que atendesse às aspirações da categoria.

Em 1962, o então Conselho Federal de Educação elaborou o Parecer/ CFE n 271/62 que fixou um novo currículo mínimo do Curso de Enfermagem.

Em reação às determinações desse novo currículo, a Associação Brasileira de Enfermagem, através do Ofício n $n^{0} 115$ de 27 de outubro de $1962^{(6)}$, solicitou ao, então, Conselho Federal de Educação, que sustasse a homologação daquele Parecer, ao tempo em que apresentou uma exposição de motivos, propondo alterações substanciais do mesmo. Essas propostas, contudo, não obtiveram eco, sendo mantidas, em essência, as distorsões do novo currículo adotado, ou seja, foi mantida a graduação do curso em três anos letivos, a exclusão das disciplinas Enfermagem de Saúde Pública e Ciências Sociais do tronco profissional comum. A ênfase passou a ser dada ao ensino das ciências físicas e biológicas, mantendose 0 enfoque na visão do homem como ser biológico, mascarando-se o aspecto social da saúde. A concepção do social foi diluída em função da concepção exclusiva do biológico e 0 ensino girava em torno do atendimento ao doente hospitalizado, tendo como marco de referência o predomínio das medidas curativas em saúde.

As profissionais de enfermagem, insatisfeitas com o novo currículo adotado, não se submeteram passivamente às determinações do, então, Conselho Federal de Educação e, através da ABEn, levantaram questionamentos acerca do currículo. Todavia, essa luta encontrava-se limitada ao horizonte restrito que o momento político the conferia, na segunda metade da década de 60 . Assim, as enfermeiras manifestavam suas insatisfações, dentro dos limites estabelecidos, através de congressos, seminários, ciclos de debates.

Os anos 60 foram marcados pelas lutas reivindicatórias da ABEn em torno do ensino da enfermagem, buscando-se a preservação dos princípios norteadores e conteúdos específicos da formação profissional da enfermagem. Nesse sentido, foram conjugados esforços entre a ABEn e as Escolas de Enfermagem, que desenvolveram trabalhos junto ao Ministério da Educação e Cultura e Conselho Federal de Educação(2,3).

Em 1968, com a Reforma Universitária (Lei no 5.540/68), a ABEn, juntamente com as Escolas de Enfermagem, passaram à revisão do currículo, com vistas à apresentação de sugestões para uma nova legislação curricular.

Em 1972, um novo currículo mínimo é formalizado, através do Parecerl CFE n 163/72 e da Resolução/CFE n 04/72, que dispunham sobre a nova estrutura curricular para o curso de graduação em enfermagem e a formação profissional da enfermeira, abrangendo as ciências básicas, as disciplinas profissionais e as habilitações específicas - enfermagem de saúde pública, enfermagem obstétrica e enfermagem médico-cirúrgica, 
incluindo, ao lado dessas, a Licenciatura em Enfermagem ${ }^{(1,2)}$.

Esse novo currículo demandou discussões polêmicas e esforços desenvolvidos, regional e nacionalmente, pela categoria, através de eventos promovidos pela ABEn, em parceria com a Comissão de Especialistas de Enfermagem da SESu/MEC, na segunda metade da década de 80. Dentre esses eventos destacaram-se os Seminários Nacionais e Regionais sobre "Perfil e Competência de Enfermeiros" e as reuniões que propiciaram a elaboração da "Proposta de Currículo Mínimo de Enfermagem".

As discussões promovidas pela ABEn, com a participação das Diretorias de Educação das suas Seções Estaduais e de representantes docentes e discentes das Escolas/Cursos de Graduação em Enfermagem e de enfermeiras dos serviços de saúde, ofereceram subsídios ao, então, Conselho Federal de Educação, que formalizou um novo currículo mínimo por meio do Parecer/CFE n⿳0 314/94 que foi regulamentado pela Portaria MEC no 1721/94.

Após dois anos de criação desse currículo, a Lei de Diretrizes e Bases da Educação Nacional (LDB) - Lei no 9394/96, em seu Artigo 53, atribuiu ao MEC a prerrogativa de fixar os currículos dos seus cursos e programas, por meio das Comissões de Especialistas do Ensino de Graduação, estabelecendo propostas de Diretrizes Curriculares Nacionais.

Considerando esse conteúdo da LDB e o momento de transição política vivido no país, a ABEn se mobilizou para viabilizar a redefinição do processo de formação da(0) enfermeira(0), na perspectiva de formar cidadãos competentes, política e tecnicamente, para atuarem nos diversos cenários da prática profissional e contribuírem para o desenvolvimento social do país.

\section{A contribuição dos SENADEns}

$A$ ABEn, dando continuidade à sua contribuição no processo de formulação de políticas de formação de Recursos Humanos em Saúde, e compreendendo a necessidade de criar um espaço amplo para discussão das questões relativas à educação em enfermagem, criou o "Seminário Nacional de Diretrizes para a Educação em Enfermagem no Brasil" (SENADEn), sendo, o primeiro, realizado em 1994.

A compreensão da necessidade desse espaço encontrou respaldo no Edital $n^{\circ} 4 / 98$ da SESu/MEC, que abriu o debate buscando a mobilização de todos os interessados na educação superior, acerca da construção das Diretrizes Curriculares indicadas pela LDB.

Nessa mobilização, a ABEn promoveu discussões acerca da necessidade de se propor e implantar Diretrizes Curriculares capazes de viabilizarem o desenvolvimento de competências e habilidades que extrapolem o simples domínio dos saberes disciplinares, visando contribuir para o processo de construção de projetos pedagógicos que, além da organização curricular, contemplem a formação de profissionais que atendam às demandas sociais ${ }^{(3)}$.

Em março de 1998, a ABEn promoveu o $3^{\circ}$ SENADEn, realizado na cidade do Rio de Janeiro, que teve como tema central "As Diretrizes para a Educação em Enfermagem no contexto da LDB". Este evento teve como principal finalidade: discutir o processo ensino-aprendizagem da Enfermagem, em seus diferentes níveis, à luz da LDB, tendo como perspectiva a formulação de propostas de diretrizes curriculares para a formação dos profissionais de enfermagem ${ }^{(4)}$.

A escolha do tema central do $3^{\circ}$ SENADEn se deu por conta da publicação do Edital $n^{\circ} 4 / 98$ da SESu/MEC, que requeria pronunciamento da categoria, com o propósito de subsidiar as escolas/cursos de graduação em enfermagem e a ABEn, para uma manifestação organizada e consensual pela categoria, junto ao Ministério da Educação.

Dando continuidade ao processo de discussão, a ABEn promoveu o $4^{\circ}$ SENADEn, realizado em Fortaleza - Ceará em abril/2000, que teve como tema central "Tendências e Perspectivas Político-Pedagógicas para o Ensino de Enfermagem", num esforço de contribuir para que as escolas/ cursos pudessem propor e implementar projetos pedagógicos que propiciassem a formação de um profissional generalista, crítico e reflexivo para atender à demanda social(3).

Dentre as várias recomendações contidas no relatório do $4^{\circ}$ SENADEn, destacam-se:

"Deve haver um empenho contínuo e efetivo da ABEn em torno dos profissionais de enfermagem e das instituições de formação de recursos humanos em enfermagem, bem como no que se refere ao conjunto de políticas e propostas que emanam do Sistema Único de Saúde, para estabelecer estratégias e mecanismos que concretizem a articulação dos três níveis de formação em enfermagem"(3).

Com a LDB, foram reativadas, também, as discussões sobre 0 processo de avaliação da educação superior ao nível da SESu/MEC.

O $5^{\circ}$ SENADEn, realizado em São Paulo, em julho/2001, teve como tema central: "A avaliação no contexto das Diretrizes Curriculares para a Educação em Enfermagem: prioridades, implicações e desafios".

Este evento contou com ampla discussão em torno da temática central, onde se incluíram os temas: Avaliação de Competência - processo ensinoaprendizagem, Avaliação de Competências - habilidades e conhecimentos, Políticas de Formação de Recursos Humanos em Enfermagem e Exame Nacional de Cursos: implicação para enfermagem.

Vale registrar que nos três dias posteriores à realização do $5^{0}$ SENADEn, foi realizada a $1^{\text {a }}$ Oficina da Comissão de Especialistas de Ensino de Enfermagem da Secretaria de Ensino Superior do Ministério da Educação (CEEEnf/SESu/MEC - Portaria 1518/2000), em pareceria com a ABEn, cuja temática foi "Construindo Padrões de Qualidade para os Cursos de Graduação em Enfermagem - Bacharelado". A Comissão organizadora desta oficina foi composta pela Presidente da ABEn, pela CEEEnf/SESu/MEC e pela Comissão Permanente de Educação / Diretoria de Educação da ABEn - Nacional. Nesta oficina foram validados os "Roteiros para Autorização e Reconhecimento de Cursos de Graduação em Enfermagem", propostos pela CEEEnf/SESu/MEC - Portaria 1518/ 2000. Nessa oportunidade foi, também, aprovado o Edital n 01/2001 da CEEEnf/SESU/MEC e ABEn - Portaria 1518/2000, referente ao Processo Seletivo de Consultor "ad hoc" da SESu/MEC, para constituição de seu Banco de Dados.

A proposta inicial dos SENADEns foi para realização bienal. Entretanto, devido à importância da sua contribuição para o processo de formação $\mathrm{da}(0)$ enfermeira(0), a categoria solicitou à ABEn que a realização desse evento se desse anualmente. Assim, a partir do ano de 2002, os SENADEns passaram a acontecer anualmente.

Nesse ano de 2006, a ABEn realiza o $10^{\circ}$ SENADEn, em Brasília, comemorando os 80 anos dessa entidade representativa das(os) enfermeiras(os).

\section{A ABEn E AS DIRETRIZES CURRICULARES NACIONAIS DO CURSO DE GRADUAÇÃO EM ENFERMAGEM}

\section{A participação na construção das Diretrizes Curriculares do Curso de Graduação em Enfermagem}

A ABEn, representada pela sua diretoria nacional, em especial pela Presidente daABEn e pela Diretora de Educação, sempre procurou manter um bom relacionamento com a CEEEnf/SESU/MEC. Vale destacar que duas presidentes da ABEn Nacional foram, também, presidentes da CEEEnf/SESu/MEC, nos períodos de 1996 a 1998 e de 1998 a 2000, respectivamente.

A primeira Comissão (gestão 1996-1998) produziu a proposta "Critérios de qualidade para a avaliação e reconhecimento dos cursos de graduação em enfermagem". A segunda Comissão (gestão 1998-2000) foi incumbida de aprimorar a proposta acima referida e, ainda, apresentar uma proposta de "Diretrizes Curriculares do Curso de Graduação em Enfermagem" com base na orientação do Conselho Nacional de Educação e da LDB. 
Essa segunda comissão (gestão 1998-2000) elaborou a proposta de "Enquadramento das Diretrizes Curriculares Nacionais do Curso de Graduação em Enfermagem" e atualizou a proposta "Critérios de Qualidade para a avaliação e reconhecimento dos cursos de Graduação em Enfermagem"(5). Com base no Edital n ${ }^{0} 4 / 98$ da SESu/MEC, em abril de 1999, essa comissão encaminhou a proposta de "Enquadramento das Diretrizes Curriculares Nacionais do Curso de Graduação em Enfermagem" para a $A B E n$, a fim de que se abrisse um debate acerca da proposta. Nesse sentido, a ABEn, encaminhou a proposta da Comissão (gestão 1998-2000) para as vinte e cinco seções que compõem a entidade, sugerindo a realização de reuniões com coordenadores de cursos de seus respectivos Estados, para pronunciamento e contribuições à referida proposta.

As seções estaduais foram surpreendidas, ao tomarem conhecimento da proposta de "Enquadramento das Diretrizes Curriculares Nacionais do Curso de Graduação em Enfermagem", pois não viram contempladas, nessa proposta, as contribuições emanadas das discussões coletivas da categoria.

Em abril de 1999, a ABEn realizou, na sua sede, em Brasília/DF, um Seminário para discussão da proposta de "Enquadramento das Diretrizes Curriculares Nacionais do Curso de Graduação em Enfermagem", apresentada pela CEEEnf (gestão 1998-2000). Esse Seminário contou com a participação dos membros dessa Comissão, bem como de docentes que representavam as seções de seus Estados e de quatro membros da Diretoria Nacional da ABEn. A reunião foi muito tensa e as discussões, em alguns momentos, foram permeadas por posicionamentos emocionados, na defesa dos aspectos e propósitos já pactuados em outras reuniões que trataram do tema. Apesar do clima de tensão, se conseguiu aprovar algumas contribuições a serem incorporadas à proposta apresentada pela Comissão (gestão 1998-2000).

A ABEn proporcionou outras discussões durante 0 ano de 1999, no entanto, a grande contribuição veio da Reunião de Escolas e Cursos de Graduação, realizada durante $051^{\circ}$ Congresso Brasileiro de Enfermagem e $10^{\circ}$ Congreso Panamericano de Enfermeria, realizados em FlorianópolisSC. Nessa reunião, foi amplamente discutida a proposta apresentada pela CEEEnf (gestão 1998-2000). As discussões pautaram-se nos posicionamentos da categoria, expressos no Relatório Final do $3^{\circ}$ SENADEn, Documento do Fórum de Escolas de Enfermagem do Estado do Rio de Janeiro, Carta da Bahia (ABEn/BA) e Carta de Natal (ABEn/ $\mathrm{RN})$. Os resultados dessas discussões originaram a Carta de Florianópolis ${ }^{(7)}$, que considerou a proposta de "Enquadramento das Diretrizes Curriculares do Curso de Enfermagem" como um texto técnico, que ignorava todo um processo de discussão e produção democrática efetivada pela categoria sobre o modelo pedagógico de ensinar e aprender em enfermagem. Foi considerado, também, que o conteúdo da proposta negava às Instituições de Ensino Superior (IES) o direito de implementar o seu próprio projeto pedagógico, além de dificultar a formação integral do profissional, fragmentando o processo ensino-aprendizagem, descaracterizando a articulação entre o ensino, a pesquisa, a assistência e a extensão. Foi considerado, ainda, que a proposta abria possibilidades para a especialização precoce, além de inserir a modalidade de curso seqüencial, modalidade esta não aceita pela categoria ${ }^{(7)}$.

Como se pode observar, houve uma rejeição da categoria frente à proposta apresentada pela, então, CEEEnf (gestão 1998-2000).

Nesse mesmo ano de 1999, a SESu/MEC tornou público o Edital 06 de 29/12/1999, buscando a renovação das Comissões de Especialistas de Ensino para as diversas áreas do conhecimento. Através desse Edital, a SESu/MEC, normatizando o processo de indicação de nomes para compor as novas Comissões de Especialistas de Ensino, solicitou às IES e entidades de Classe, indicações de docentes para comporem as suas Comissões de Especialistas de Ensino, nos termos do disposto no Art. $4^{\circ}$ da Portaria Ministerial no 972 de 22/08/97. Esse procedimento foi adotado para garantir a participação efetiva da categoria na indicação de nomes de docentes que representassem os Cursos de Graduação.

Cada IES teve a possibilidade de indicar dois nomes de docentes. Dos nomes indicados pelas IES, na área da Enfermagem, a ABEn apoiou o nome de cinco docentes. Dos nomes apoiados pela ABEn, dois (lara de Moraes Xavier e Josicelia Dumêt Fernandes) foram escolhidos pela SESul MEC para comporem a nova CEEEnf/SES/MEC, que foi designada pela Portaria SESu/MEC 1518 de 14/6/2000. Essa Comissão foi assim constituída: Iara de Moraes Xavier (UNIRIO) - Coordenadora, Josicelia Dumêt Fernandes (UFBA), Maria Helena Cappo Bianco (USC) e Maria Isabel Pedreira de Freitas Ceribelli (UNICAMP).

Essas docentes, ao assumirem a nova CEEEnf/SESu/MEC (Portaria $n^{0} 1518$ de 14/6/2000), tomaram conhecimento da diversidade e complexidade da questão da proposta de Diretrizes Curriculares da área, o que exigia um novo delineamento para o âmbito específico da enfermagem. Essa Comissão, sensível às criticas e sugestões da categoria em relação às propostas de Diretrizes Curriculares já encaminhadas ao Conselho Nacional de Educação (CNE) pela Comissão anterior e, ainda, com base no processo democrático e de vivência do exercício da cidadania, debruçou-se sobre a proposta originária da categoria, explicitada na "Carta de Florianópolis". Nesse direcionamento, a CEEEnf/SESu/MEC (Portaria no 1518 de 14/6/2000), assumiu, em parceria com a ABEn, através de sua Diretoria de Educação, um trabalho coletivo com profissionais da área, para a construção de uma nova proposta de Diretrizes Curriculares para o Curso de Graduação em Enfermagem.

Para o consenso do documento final da nova proposta de Diretrizes Curriculares do Curso de Graduação em Enfermagem, aABEn e a CEEEnf/ SESu/MEC (Portaria no 1518 de 14/6/2000) tomaram, como base, a "Carta de Florianópolis" (1999), os resultados das discussões do $4^{0}$ SENADEn (2000), da Reunião de Cursos e Escolas de Graduação em Enfermagem do $52^{\circ}$ Congresso Brasileiro de Enfermagem (2000) e do $5^{\circ}$ SENADEn (2001), evidenciando uma aderência às reivindicações e posições da enfermagem nacional defendidas pela categoria.

Essa nova proposta foi encaminhada, para fins de aprovação, ao CNE, através do Ofício n ${ }^{\circ} 11876$ do Diretor do Departamento de Ensino Superior da SESu/MEC, em 17/10/2000.

O CNE passou a ter, portanto, duas propostas de Diretrizes Curriculares Nacionais para o Curso de Graduação em Enfermagem, as quais possuíam pontos de divergência muito evidentes.

A ABEn, juntamente com a CEEEnf/SESu/MEC (Portaria no 1518 de 14/6/2000), acompanhou o processo de tramitação da proposta de Diretrizes Curriculares Nacionais para o Curso de Graduação em Enfermagem junto ao CNE.

Por outro lado, o Conselho Nacional de Saúde (CNS), interessado na questão da formação de Recursos Humanos para a Saúde, encaminhou, ao CNE, um pedido de audiência publica para discutir as Diretrizes Curriculares das profissões da saúde, antes da aprovação das mesmas. Solicitou, ainda, parecer sobre a matéria à Comissão Intersetorial de Recursos Humanos, o que revelou uma preocupação desse órgão deliberativo com os rumos da formação de Recursos Humanos em Saúde no país e um apoio importante ao movimento pelas mudanças no campo estratégico do Sistema Único de Saúde (SUS). Frente a essa solicitação, emergiu uma ampla mobilização sobre 0 assunto, envolvendo IES, entidades profissionais e sociedade civil, evidenciando uma sintonia entre os mesmos e criando um contato externo favorável à discussão, reflexão e capacidade propositiva na busca da transformação do processo de formação de recursos humanos para a saúde.

A audiência pública contou com a análise de representantes da ABEn, da CEEEnf/SESu/MEC (Portaria $n^{0} 1518$ de 14/6/2000) e do Conselho Nacional de Saúde, dentre outros.

Em 07 de novembro de 2001, essa nova proposta, originária da mobilização dos profissionais da enfermagem, através da ABEn, foi 
aprovada e transformada na Resolução CNE/CES No 3 de 7/11/2001 ${ }^{(8)}$.

\section{A sustentabilidade das Diretrizes Curriculares do Curso de Graduação em Enfermagem}

Com a aprovação das Diretrizes Curriculares Nacionais do Curso de Graduação em Enfermagem (DCENF) - Resolução CNE/CES № 3 de 71 11/2001, a ABEn buscou formas de garantir a implantação/implementação dessas Diretrizes nos diversos do cursos do país. Nesse sentido, a ABEn realizou o "Programa de Sustentabilidade para Implantação das Diretrizes Curriculares dos Cursos de Graduação em Enfermagem", através de acordo de serviços contratuais celebrados com a Organização PanAmericana de Saúde e com a parceria da Secretaria de Políticas de Saúde do Ministério da Saúde. Esse Programa teve como objetivo potencializar os movimentos desenvolvidos nas escolas/cursos de enfermagem, na perspectiva de transformação da formação de enfermeiras(os) como sujeitos da construção do modelo de atenção à saúde, produção de conhecimentos e prestação e serviços voltados para as necessidades do SUS e sua consolidação $0^{(9)}$.

Esse Programa teve como eixos estruturantes: capacitação dos sujeitos e dos processos, com base na abordagem crítica das competências e da promoção em saúde, impulsionadoras de mudanças político-pedagógicas na formação das(os) enfermeiras(os); construção de sujeitos coletivos nos espaços institucionais e dos movimentos sociais, para atuação crítico-propositiva na implantação das Diretrizes Curriculares dos Cursos de Graduação em Enfermagem; discussão de concepções e propostas de avaliação, entendida como estratégia de regulação do desenvolvimento político, institucional e da aprendizagem individual; discussão de proposições pactuadas sobre a regulação e regulamentação da prática social de enfermagem, frente aos impactos estimulados pelo paradigma da promoção/integralidade em saúde, as transformações no processo de produção de serviços e a necessária ampliação e diversificação do elenco de competências da enfermagem e da(0) enfermeira(0)(9).

A ABEn, através do Programa de Sustentabilidade para Implantação das Diretrizes Curriculares dos Cursos de Graduação em Enfermagem, possibilitou o investimento em um expressivo elenco de atividades e eventos locais, estaduais, regionais e nacionais, além de publicações que disseminaram a produção individual e coletiva oriundas das diversas regiões do país, expressando as reflexões e ações propostas ou desenvolvidas pelas instituições formadoras e de serviços. Dentre essas atividades, destacam-se: criação, reativação e fortalecimento dos Fóruns de Escolas de Enfermagem nas diversas seções estaduais; seminários sobre Diretrizes Curriculares dos Cursos de Graduação em Enfermagem, com ênfase na construção de Projetos Pedagógicos de Cursos e concepção de competências e habilidades; debates sobre as bases do fazer pedagógico; oficinas de sensibilização estimulando a construção de sujeitos coletivos nos espaços institucionais para a transformação do processo de formação de enfermeiras(os); seminários sobre avaliação educacional: concepções, políticas e alternativas; oficinas para apresentação e debates de experiências de implantação/implementação das DCENF; discussões para definição de estratégias de capacitação dos sujeitos e dos processos, com base na abordagem crítica das competências e da promoção da saúde; debates sobre a duração dos cursos de graduação, sobre a dimensão político-pedagógica e desafios do processo de mudança; discussões sobre os diversos cenários das práticas pedagógicas, assim como discussões sobre a formação da(0) enfermeira(0) e sua interface com os serviços de saúde ${ }^{(9)}$.

$O$ conjunto dessas e de outras atividades desenvolvidas demonstram a abrangência expressiva da ABEn no campo da educação em
Enfermagem.

As ações de sustentabilidade para implantação/implementação das DCENF, desenvolvidas pela ABEn, são, portanto, uma construção processual cujos atores sociais estão comprometidos com a construção de novas possibilidades de ensinar e aprender em Saúde/Enfermagem.

\section{O ACOMPANHAMENTO DO PROCESSO E FORMAÇÃO DA(O) ENFERMEIRA(O)}

Consciente de que mudanças só se constroem com parcerias e que é necessário construir coletivamente essas mudanças, $A B E n$ continua realizando discussões em seus eventos regionais e nacionais, dando continuidade à sua política de acompanhamento da implantação das DCENF, nas Escolas e Cursos de Graduação em Enfermagem, em todo o território nacional, reafirmando o seu compromisso contínuo na luta por uma educação que atenda à demanda social $\mathrm{e}$ aos anseios da categoria. Este tem sido um desafio a ser enfrentado e, para isso a $A B E n$ entende que esta atividade demanda muito trabalho e tempo, pois envolve a definição de bases teóricas e filosóficas e de marcos conceituais indispensáveis à consecução dos objetivos propostos. $O$ enfrentamento a esse desafio é permeado por divergências por conta de princípios, valores e tendências diversificados, o que por certo dificulta, sem, contudo, inviabilizar o trabalho.

Na perspectiva de manter o diálogo constante e permitir a elaboração de propostas efetivas, a ABEn tem oferecido, em todos os seus eventos, um espaço de destaque para as discussões relativas à educação e, assim, vem proporcionando a todos os profissionais da enfermagem, oportunidades para o debate político, franco e ético, favorecendo a análise, a avaliação e troca de experiências entre os que se mostram comprometidos/responsáveis com a educação na área da enfermagem.

A ABEn, tendo a causa da educação como prioridade, está em constante busca para mobilizar esforços a fim de agregar enfermeiras(OS) docentes e assistenciais, bem como estudantes de enfermagem, com 0 objetivo de discutir e consolidar um projeto educacional que atenda à demanda social. Para tanto, continua promovendo encontros, fóruns de debates, oficinas, seminários nacionais e regionais, buscando incentivar a participação efetiva de todos os interessados e envolvidos na educação em enfermagem.

A ABEn tem tido, portanto, um importante papel no processo de formação da(0) enfermeira(0), enquanto articuladora/mediadora na formulação de estratégias coletivamente construídas para o fortalecimento do movimento de mudanças nos órgãos formadores e prestadores de serviços de saúde.

Faz-se necessário explicitar que o trabalho da $A B E n$, no que se refere à educação, não é um trabalho isolado. Ele tem sido realizado em parceria com outras entidades como a Rede Unida, a Federação Nacional dos Enfermeiros, a Associação Brasileira de Educação Médica e com setores dos Ministérios da Educação e da Saúde, que se empenham em contribuir na formação de profissionais da saúde competentes e habilitados para intervir no processo saúde-doença da população, atendendo, assim, à demanda social.

Para concluir, registramos que esse texto atende à necessidade de se resgatar parte da história da Enfermagem Brasileira, particularmente da área da educação em enfermagem e que esta se confunde com a história da $A B E n$, pois esta entidade, desde a sua criação, sempre se manteve vigilante no acompanhamento de todas as propostas e ações que dizem respeito à educação, opinando, refletindo, construindo $\mathrm{e}$ intervindo de forma competente, proativa e ética. 
Vale EG, Fernandes JD.

\section{REFERÊNCIAS}

1. Carvalho ACC. Associação Brasileira de Enfermagem, 1926-1976: documentário. Brasília (DF): Folha Carioca; 1976.

2. Fernandes JD. O ensino de enfermagem e de enfermagem psiquiátrica no Brasil (dissertação). Salvador (BA): Departamento de Medicina Preventiva da Faculdade de Medicina, Universidade Federal da Bahia. Salvador; 1982.

3. Paiva MS. Enfermagem Brasileira: contribuição da ABEn. Brasília (DF): ABEn-Nacional; 1999

4. Vale EG. Novas diretrizes para o Ensino de Graduação em Enfermagem In: Anais do $4^{\circ}$ Seminário Nacional de Diretrizes para a Educação em Enfermagem. Fortaleza (CE), Brasil. Fortaleza (CE): ABEn-CE; 2001. p. 37-47.

5. Rossi MJS. A propósito do movimento participação. Rev Bras Enferm 2001; 53(4): 213-28.
6. Associação Brasileira de Enfermagem. Relatório de Atividades Gestão 1998/2001. Brasília (DF): ABEn; 2001

7. Associação Brasileira de Enfermagem. Carta de Florianópolis: Enquadramento das Diretrizes Curriculares do Curso de Enfermagem. Olho Mágico1999; 5: 27-30.

8. Ministério da Educacão. Conselho Nacional de Educação. Câmar de Educação Superior. Resolução CNE/CES no 3 de 7/11/2001: Diretrizes Curriculares Nacionais do Curso de Graduação em Enfermagem. Brasília (DF); Ministério da Educação; 2001.

9. Associação Brasilieira de Enfermagem. Programa de sustentabilidade para a implantação das Diretrizes Curriculares dos Cursos de Graduação em Enfermagem. Relatório Final. Brasília (DF): ABEn/OPAS; 2003 